\title{
Anterior Wall of the Nasopharynx
}

National Cancer Institute

\section{Source}

National Cancer Institute. Anterior Wall of the Nasopharynx. NCI Thesaurus. Code C12245.

The anterior aspect of the nasopharynx. 